\title{
Simulation Tool for Variably Saturated Flow with Comprehensive Geochemical Reactions in Two- and Three-Dimensional Domains
}

\author{
L. Wissmeier*, D.A. Barry \\ Ecole Polytechnique Fédérale de Lausanne (EPFL) \\ Laboratoire de Technologie Ecologique \\ Station 2, CH-1015 Lausanne, Switzerland
}

Resubmitted on 17 August 2010 to Environmental Modelling \& Software

* Author to whom all correspondence should be addressed. Telephone: +41 21693 5727, facsimile: +41 216938035

E-mail addresses: laurin.wissmeier@epfl.ch (L. Wissmeier), andrew.barry@epfl.ch (D.A. Barry) 


\section{Abstract}

2 We present a software tool for simulations of flow and multi-component solute transport in

3 two and three-dimensional domains in combination with comprehensive intra-phase and

4 inter-phase geochemistry. The software uses IPhreeqc as a reaction engine to the multi-

5 purpose, multidimensional finite element solver COMSOL Multiphysics ${ }^{\circledR}$ for flow and

6 transport simulations. Here we used COMSOL to solve Richards' equation for aqueous phase

7 flow in variably saturated porous media. The coupling procedure presented is in principle

8 applicable to any simulation of aqueous phase flow and solute transport in COMSOL. The

9 coupling with IPhreeqc gives major advantages over COMSOL's built-in reaction capabilities,

10 i.e., the soil solution is speciated from its element composition according to thermodynamic

11 mass action equations with ion activity corrections. State-of-the-art adsorption models such

12 as surface complexation with diffuse double layer calculations are accessible. In addition,

13 IPhreeqc provides a framework to integrate user-defined kinetic reactions with possible

14 dependencies on solution speciation (i.e., $\mathrm{pH}$, saturation indices, and ion activities), allowing

15 for modelling of microbially mediated reactions. Extensive compilations of geochemical

16 reactions and their parameterization are accessible through associated databases.

\section{Keywords}

18 Geochemistry, Reaction, PHREEQC, IPhreeqc, Richards' Equation, Unsaturated Flow,

19 COMSOL, Solute Transport

\section{Research highlights}

21 - Coupling of COMSOL and PHREEQC facilitates simulation of variably saturated flow with comprehensive geochemical reactions.

- The use of finite elements allows for the simulation of flow and solute transport in complex 2 and 3D domains.

- Geochemical reactions are coupled via sequential non-iterative operator splitting.

- The software tool provides novel capabilities for investigations of contaminant behaviour in variably saturated porous media and agricultural management. 


\section{Software requirements}

29 COMSOL Multiphysics ${ }^{\circledR}$ including Earth Science Module (tested version: 3.5a; due to a

30 memory leak in versions 4.0 and 4.0a, these are not suitable for the presented coupling)

31 Price for single user academic license including Earth Science Module ca. $2000 €$

32 Matlab $^{\circledast}$ (tested versions: 7.9, 7.10)

33 Price for single user academic license including Parallel Computing Toolbox ca. $650 €$

34 IPhreeqc (COM-version, available free of charge at

35 http://wwwbrr.cr.usgs.gov/projects/GWC_coupled/phreeqc/)

36 The coupling files together with animations of the presented simulations are available at

37 http://infoscience.epfl.ch/record/143469 (link: download fulltext) 


\section{Introduction}

39 Computer simulations of water availability and quality play an important role in state-of-

40 the-art water resources management and agriculture (Barry, 1992; Šimůnek and Bradford,

41 2008). Due to the importance of the unsaturated zone as the major life-supporting

42 ecosystem on land (Brussaard et al., 2007), there is a great demand for understanding and

43 predicting the complex interactions between highly non-linear vadose zone flow and bio-

44 geochemical reactions (Wissmeier et al., 2009). However, many of the most utilized

45 software programs focus either on physical flow and transport phenomena (e.g., MODFLOW

46 (Harbaugh et al., 2000), SUTRA (Voss and Provost, 2008), HYDRUS (Šimůnek et al., 2009)), or

47 on geochemical reactions (e.g., MINTEQ (Gustafsson, 2010), CHESS (van der Lee, 1998),

48 ORCHESTRA (Meeussen, 2003)). Saturated flow codes have been coupled with geochemical

49 reaction packages to produce combined water flow, multispecies transport and complex

50 geochemical reactions (e.g., PHT3D (Prommer et al., 1999), DART (Freedman and Ibaraki,

51 2002), PHAST (Parkhurst et al., 2004), PHWAT (Mao et al., 2006). In recent years, simulation

52 tools for unsaturated porous media flow with detailed geochemistry have emerged (HP1

53 (Šimůnek et al., 2009), RICH-PHREEQ (Wissmeier and Barry, 2010)). Although powerful tools,

54 the applicability of the aforementioned unsaturated flow/transport/reaction models is

55 restricted to systems with one-dimensional movement of water and solutes.

56 The coupling of COMSOL (COMSOL Multiphysics ${ }^{\circledR}, 2010$ ) and IPhreeqc (Charlton and

57 Parkhurst, 2010) presented here extends the capabilities of these models by combining

58 unsaturated porous media flow in two and three dimensions with comprehensive

59 geochemical reactions. IPhreeqc is a version of PHREEQC (Parkhurst and Appelo, 1999) that

60 is specifically designed for coupling to multicomponent transport simulators. While it retains

61 all of PHREEQC's reaction capabilities, IPhreeqc provides additional methods for data

62 manipulation and communication to the host application. The coupled model's main

63 features are listed below.

64 Unsaturated Flow:

65 - Constitutive relations according to van Genuchten (1980), Brooks and Corey (1964) or

66 user-defined

67 - Anisotropic unsaturated conductivity 
- Specific storage according to fluid compressibility or user-defined storability function

- Fluid density, viscosity and liquid source term through user-defined expressions with possible dependencies on COMSOL variables

\section{Multispecies Solute Transport:}

- Dispersivity in directions parallel and orthogonal to flow

- Tortuosity according to Millington and Quirk (1961) or user-defined

- Species independent coefficient of molecular diffusion and dispersivities

- Liquid source concentrations and solute sources through user-defined expressions with possible dependencies on COMSOL variables

\section{Geochemical Reactions:}

- Equilibrium solution speciation and redox reactions

- Equilibrium mineral dissolution/precipitation

- Ion exchange on permanently charged adsorption sites

- Surface adsorption according to the diffuse double layer model (Dzombak and Morel, 1990) or the CD_MUSIC model (Hiemstra et al., 1989) with or without explicit calculation of the diffuse double layer composition

- Kinetic reactions according to user-defined rate equations, with possible dependencies on solution speciation, temperature or moisture content

- Gas phase exchange

- Solid solutions

A considerable advantage of the coupling results from the flexibility of COMSOL to define any input parameter as a function of internal variables. For example, root water uptake, entered as a negative liquid sources term, can be defined by a function of space coordinates and liquid phase pressure head. In addition, IPhreeqc's capabilities to integrate user-defined rate expressions allows for the simulation of complex time-dependent geochemical reactions with explicit dependencies on solution speciation (e.g., ion activities, $\mathrm{pH}$, mineral saturation). With these capabilities, the presented model is significantly more comprehensive than existing codes in the field of unsaturated reactive transport modelling, such as MIN3P (Mayer et al., 2002) and RETRASO (Saaltink et al., 2004). The model setup is 
97 greatly facilitated by graphical user interfaces for flow and transport (COMSOL) and

98 reactions (PHREEQC).

99 This paper is organized as follows. Section 2 briefly describes the underlying theory of

100 component-based phase flow, section 3 illustrates the coupling procedure, and sections 4

101 and 5 provide application examples for kinetic pesticide degradation and fertigation via a

102 subsoil drip irrigation system (files for these cases are available for download).

\section{Theory}

104 In the presented scheme, the classical advection diffusion/dispersion equation was used for

105 multi-component solute transport (Bear, 1972, 2007; Bear and Bachmat, 1998),

$\frac{\partial \theta c_{i}}{\partial t}=-\nabla \cdot\left(\boldsymbol{q} c_{i}\right)+\nabla \cdot\left(\theta \overline{\overline{\boldsymbol{D}}} \boldsymbol{\nabla} c_{i}\right)$

106 where $\theta$ is the relative liquid phase saturation $\left(\mathrm{m}^{3} \mathrm{~m}^{-3}\right), c_{i}\left(\mathrm{~kg} \mathrm{~m}^{3}\right)$ is the concentration of

107 solution species $i, \boldsymbol{q}\left(\mathrm{m} \mathrm{s}^{-1}\right)$ is the Darcy flux and $\overline{\bar{D}}\left(\mathrm{~m}^{2} \mathrm{~s}^{-1}\right)$ is the hydrodynamic dispersion

108 tensor.

109 Recognizing that the liquid phase is composed of solution species according to

$\theta=\frac{\sum_{i} n_{i} m_{i}}{\rho}$

110 where $n_{i}\left(\mathrm{~mol} \mathrm{~m}^{3}\right)$ is the moles of solution species $i$ in a control volume with a molar weight

$111 m_{i}\left(\mathrm{~kg} \mathrm{~mol}^{-1}\right)$, the application of Eq. (1) to all solution species in the liquid phase effectively

112 yields phase mass balance according to

$\frac{\partial \rho \theta}{\partial t}=-\nabla \cdot \rho \theta v$

113 where $\boldsymbol{v}$ is the barycentric mass flow velocity of the liquid phase (Corey and Auvermann,

114 2003). This implies that the net mass flux induced by diffusion/dispersion (Letey et al., 1969)

115 can be neglected, which is a common assumption (Jacques and Šimůnek, 2010; Miller et al.,

116 1998; Šimůnek et al., 2006; Šimůnek et al., 2009). 
117 In the presented scheme, the Darcy flux $\boldsymbol{q}=\boldsymbol{v} \theta\left(\mathrm{m} \mathrm{s}^{-1}\right)$ in is computed from Richards'

118 equation according to

$$
\boldsymbol{q}=\frac{\overline{\overline{\boldsymbol{K}}}}{\rho g}(\boldsymbol{\nabla} p+\rho g \boldsymbol{\nabla} z),
$$

119 (e.g., Bear, 1972, 2007), where $\overline{\bar{K}}$ is the unsaturated hydraulic conductivity tensor $\left(\mathrm{m} \mathrm{s}^{-1}\right), p$

120 is the fluid pressure $\left(\mathrm{kg} \mathrm{m}^{-1} \mathrm{~s}^{-2}\right)$ and $g$ is the magnitude of gravitational acceleration $\left(\mathrm{m} \mathrm{s}^{-2}\right)$.

121 The other major part of the model concerns geochemical reactions (including biological

122 reactions modelled using a geochemical approach). Thorough descriptions of the models for

123 this part are available in textbooks (Appelo and Postma, 2005; Langmuir, 1997) and the

124 PHREEQC manual (Parkhurst and Appelo, 1999).

\section{Coupling procedure}

126 In the discretized time domain of the numerical model, the three simultaneous and

127 dependent processes flow, solute transport and reaction are separated using a non-iterative

128 sequential split-operator approach where $\Delta t$ is the length of the coupling time step. The

129 coupling time step is further reduced within the iterative schemes for unsaturated flow,

130 solute transport and geochemical speciation as required by the respective algorithms. As

131 result of the decoupling, concentrations are assumed independent of reactions in solute

132 transport computations. As well, the liquid phase saturation and density are similarly

133 assumed independent of concentrations and reactions during flow calculations. During the

134 geochemical reaction step (performed within IPhreeqc), the solution composition is

135 assumed independent of both flow and transport. The influence of reaction kinetics, grid

136 size and splitting time step on the introduced splitting error in unsaturated flow situations

137 was investigated by Jacques et al. (2006). General discussions on operator splitting are

138 provided by Yeh and Tripathi (1989), Valocchi and Malmstead (1992) and Barry et al. (2000;

139 1996; 1997), among others.

140 Fig. 1. Program flow and structure.

141 Fig. 1 illustrates the program structure for the coupling of COMSOL and IPhreeqc using

142 Matlab (Matlab $\left.{ }^{\circledR}, 2010\right)$ as the controlling application and interface for the COMSOL and

143 IPhreeqc modules (grey shaded, dashed boxes). The code is organized in three major m-files 
144 (black textboxes in Fig. 1). At the beginning of the simulation, the controlling script coupling_COMSOL_PHREEQC.m runs subscripts to configure the simulation domain with

146 flow and transport properties, initializes COMSOL and IPhreeqc computations and specifies

147 boundary conditions. Geochemical properties such as $\mathrm{pH}$ and redox potential (pe) are 148 extremely sensitive to the total element concentrations. Minimal deviations of the ratio of

149 oxygen to hydrogen from the stoichiometric ratio of $1: 2$ in the simulation of pure water will 150 dramatically affect the pe, for example. Precise concentration values for initial and 151 boundary conditions in COMSOL are thus conveniently determined by preliminary PHREEQC 152 speciation calculations.

153 After the initialization procedure, computations enter the iteration loop of the split 154 operator, where COMSOL and IPhreeqc procedures alternate for the calculation of flow, 155 transport and reactions. Data from the output of one procedure is passed back to the 156 Matlab workspace and reformatted for the following procedure using the functions 157 phreeqc2comsol and comsol2phreeqc. For the computation of aqueous phase flow in 158 COMSOL, fluid pressures are calculated from the output of the preceding reaction step 159 (mass of solution in control volume, solution density, pressure-saturation relation). Darcy 160 flux velocities from flow calculations together with master species concentrations from the 161 reaction step are input into the COMSOL solute transport routine (Eq. (1)). The use of 162 master species instead of solution species considerably reduces the degrees of freedom in 163 transport calculations and therefore the numerical burden (Steefel and MacQuarrie, 1996). 164 However, it impedes the simulation of species-dependent diffusion. The comsol2phreeqc165 function retrieves the results from COMSOL as a vector of all degrees of freedom (fluid 166 pressure and element concentrations) at all nodes in the domain. The vector is reformatted 167 as a numeric Matlab array. Master species concentrations from transport calculations are 168 multiplied by moisture contents from flow calculations. This yields the aqueous phase 169 composition at each node in terms of moles of master species per control volume. In the 170 IPhreeqc reaction step, each node in the simulation domain is represented by a single batch 171 reactor that contains physical amounts (moles) of solution elements, minerals, gases and 172 adsorption sites. Since only the liquid phase composition is altered through flow and 173 transport, comsol2phreeqc only updates the solution composition using IPhreeqc's method 174 SOLUTION_MODIFY. From the ensemble of elements, the aqueous solution is speciated, and 
175 mineral reactions, surface adsorption/desorption reaction and kinetic reactions are

176 computed. After the IPhreeqc reaction procedure, flow and transport calculations in

177 COMSOL are reinitialized with the updated values of moisture content and master species

178 concentrations using the phreeqc2comsol-function. Results, which are passed back from

179 IPhreeqc to the Matlab workspace as a cell array, are reshaped as a vector with the same

180 structure of the COMSOL solution vector. COMSOL's asseminit-function is used to create

181 valid initial conditions for flow and transport calculations in COMSOL.

182 All primary master species in the liquid phase (including elemental oxygen and hydrogen)

183 must be included in solute transport calculations in order to represent flow by the transport

184 of liquid phase components. This approach has been applied in previous couplings of

185 geochemistry in PHREEQC with unsaturated flow and transport calculations (Jacques et al.,

186 2008; Wissmeier and Barry, 2010). Charge imbalance, present in initial and boundary

187 solutions or developing during reactions (e.g., surface adsorption without explicit calculation

188 of the diffuse layer composition) (Parkhurst, 2010), is treated as an extra solution

189 component in transport calculations. It is also included in speciation calculations in order to 190 accurately reproduce $\mathrm{pH}$ and pe.

191 During the conversion from units relative to an arbitrary control volume in COMSOL (e.g.,

$192 \mathrm{~m}^{3} \mathrm{~m}^{-3}$ for $\theta$ ) to physical quantities in IPhreeqc, the size of the batch reactors is taken as one

193 litre for convenience. Thus, solid phase properties in IPhreeqc, such as the moles of

194 adsorption sites and mineral phases have to be understood as per litre of unsaturated zone

195 volume (soil including pore space). Without further modifications, solid phase properties are

196 independent of water contents, i.e., the moles of mineral phases or exchange sites in

197 contact with the unsaturated soil solution do not change due to changes in moisture 198 contents.

199 Negative master species concentrations may result from oscillatory behaviour of COMSOL's

200 finite element scheme for solute transport in the vicinity of sharp concentration gradients.

201 The performance index, defined as the product of the grid Péclet number and the Courant

202 number, can be used as an indicator of oscillatory transport behaviour (Huyakorn and

203 Pinder, 1983; Perrochet and Berod, 1993; Šimůnek et al., 2009). Since IPhreeqc defines the

204 solution composition in terms of moles of elements, negative concentrations from the 
205 COMSOL-procedure are set to zero during reaction calculations. After the reaction step, 206 negative concentrations from the previous flow/transport step in COMSOL are summed to 207 the master species concentrations that are output of IPhreeqc. The summation of negative 208 concentrations from transport simulations to the results from reaction calculations avoids 209 significant mass balance errors that would otherwise result from the repeated adjustment 210 of negative output from COMSOL to zero. This procedure remedies mass balance errors.

211 Nevertheless, it is recommended to avoid oscillations in solute transport through 212 appropriate domain discretisation (Donea and Huerta, 2004; Perrochet and Berod, 1993).

213 For accurate transport of $\mathrm{pH}$ in unbuffered solutions, the relative tolerance of the solute 214 transport scheme in COMSOL is set to $10^{-10}$. In order to decrease the absolute tolerance for 215 oxygen and hydrogen, their nominal concentrations in COMSOL are reduced by their molal 216 concentrations in pure water $\left(55.50621679636 \mathrm{~mol} / \mathrm{kg}_{\text {water }}\right.$ and 111.0124335927

$217 \mathrm{~mol}_{\mathrm{H}} / \mathrm{kg}_{\text {water }}$, respectively). Even with this high accuracy, calculations of the redox potential 218 (pe) in unbuffered solutions may not give reliable results and should be examined carefully. 219 Equilibration with atmospheric $\mathrm{O}_{2}$ stabilizes otherwise unbuffered solutions und should 220 therefore be considered if applicable (Parkhurst and Appelo, 1999).

221 The COM-version of IPhreeqc (Charlton and Parkhurst, 2010) that is utilized in the presented 222 coupling has a number of features that greatly simplify data handling:

- Reaction calculations can be entirely controlled from within Matlab by passing 224 commands strings to the COM object.

225 - Changes in the reaction system due to transport of aqueous elements are considered by 226 modifying the moles of elements in solution.

227 - No cumbersome writing/reading of files is necessary in order to pass results from the 228 reaction module to the flow/transport module and vice versa. Data transfer via the 229 Matlab workspace is processed entirely in memory.

230 - The status of the entire geochemical system, including all exchangers, surfaces, kinetics 231 phases, mineral and gas phases, is automatically saved by the COM object in between 232 calls.

233 As result of persistence of the geochemical properties in the COM object, the coupling 234 procedure only needs to manage solution elements. This not only decreases programming 
235 effort and increases coupling efficiency but also eliminates the need for user-defined

236 definitions of all possible exchange and surface species, as is found in earlier couplings

237 involving PHREEQC (Prommer et al., 2003).

\section{Verification example: Pesticide degradation}

239 This application example reproduces the simulation of kinetic pesticide degradation in

240 COMSOL's model library (COMSOL Multiphysics ${ }^{\circledR}, 2008 \mathrm{~b}$ ) using IPhreeqc instead of

$241 \mathrm{COMSOL}^{\prime} \mathrm{s}$ Reaction Engineer $\mathrm{Lab}^{\circledR}$ to simulate the reaction chain. According to

242 COMSOL Multiphysics $^{\circledast}(2008$ b), the simulation is inspired by but does not exactly duplicate

243 the application example no. 7 of the software packages SWMS-2D (Šimůnek et al., 1994) and

244 HYDRUS-2D (Šimůnek et al., 1999). Because of the identical treatment of unsaturated flow

245 and solute transport, the application example can be regarded as a verification of the

246 coupling procedure.

Fig. 2. Simulation domain with finite element mesh for pesticide simulation. The source zone is indicated by the thick line at $y=0$.

249 The radially symmetric simulation domain with 4401 nodes and 26406 degrees of freedom is

250 displayed in Fig. 2. The pesticide Aldicarb enters the dry soil via constant flux infiltration at

251 the top boundary in the region $y=0 \mathrm{~m}, 0 \mathrm{~m} \leq r \leq 0.2 \mathrm{~m}$. The soil is divided into two

252 subdomains with different hydraulic properties, i.e., higher conductivity and lower saturated

253 water content below $y=-0.4 \mathrm{~m}$. The initial hydraulic head $h(\mathrm{~m})$ of the simulation domain is

254 given by the expression

$h(y)=\left\{\begin{aligned}-(y+1.2 \mathrm{~m}), & y<-0.4 m, \\ -(1.2 y+1.6 \mathrm{~m}), & y \geq-0.4 m .\end{aligned}\right.$

255 Transformations between Aldicarb and its breakdown products are governed by first-order

256 rates according to Eqs. (6-11), where $n_{i}$ denotes moles of the chemical in the control

257 volume $\left(\mathrm{mol} \mathrm{m}^{-3}\right), k_{1}-k_{5}$ are reaction constants $\left(\mathrm{s}^{-1}\right), c_{i}^{\prime}$ denote total molal concentrations

$258\left(\mathrm{~mol} \mathrm{~kg}_{\text {water }}{ }^{-1}\right)$ and $w$ stands for the kilograms of water in the control volume $\left(\mathrm{kg} \mathrm{m}^{-3}\right)$.

Aldicarb (a): $\quad \frac{\partial n_{\mathrm{a}}}{\partial t}=-\left(k_{1}{c^{\prime}}_{\mathrm{a}}+k_{2} c^{\prime}{ }_{\mathrm{a}}\right) w$ 
Aldicarb Oxime (ao): $\quad \frac{\partial n_{\mathrm{ao}}}{\partial t}=k_{1} c^{\prime}{ }_{\mathrm{a}} w$;

Aldicarb Sulfoxide (asx): $\quad \frac{\partial n_{\mathrm{asx}}}{\partial t}=\left(k_{2}{c^{\prime}}_{\mathrm{a}}-k_{3}{c^{\prime}}_{\text {asx }}-k_{4}{c^{\prime}}_{\text {asx }}\right) w$;

Aldicarb Sulfoxide Oxime (asxo): $\quad \frac{\partial n_{\text {asxo }}}{\partial t}=k_{3} c^{\prime}{ }_{\text {asx }} w$;

Aldicarb Sulfone (asn): $\quad \frac{\partial n_{\text {asn }}}{\partial t}=-\left(k_{4} c^{\prime}{ }_{\text {asn }}+k_{5} c^{\prime}{ }_{\text {asn }}\right) w$;

Aldicarb Sulfone Oxime (asno): $\quad \frac{\partial n_{\text {asno }}}{\partial t}=k_{5} c^{\prime}{ }_{\text {asn }} w$.

259 The reaction chain together with first-order rate constants is displayed schematically in Fig.

2603.

261 Fig. 3. Aldicarb reaction chain.

262 To be consistent with the COMSOL example, it is necessary to prevent unwanted

263 geochemical transformations. Therefore, Aldicarb and its daughter products were

264 introduced into IPhreeqc as separate uncharged solution master species with no reactions

265 apart from the transformations listed in Fig. 3. Further details of the breakdown process and

266 the COMSOL solution are available in the COMSOL model library documentation

267 (COMSOL Multiphysics ${ }^{\circledR}, 2008 \mathrm{a}$ ). The coupling time step $\Delta t$ was set to $0.1 \mathrm{~d}$.

Fig. 4. Comparison of concentrations from the coupling procedure and COMSOL alone eight $d$ after beginning of infiltration.

270 In order to verify the coupling procedure, moisture content and concentrations were

271 compared along the centre line $(r=0)$ with results from COMSOL alone (Fig. 4). Moisture

272 contents from the coupled simulation (COMSOL+IPhreeqc) and the global implicit method in

273 COMSOL (COMSOL) are visually indistinguishable. Small differences in chemical

274 concentrations can be fully attributed to the splitting error, whose magnitude decreases

275 linearly with $\Delta t$. If negative concentrations from the previous transport step are not

276 summed to the concentrations after transport, as described in section 3 , an obvious mass

277 balance error with overestimation of all pesticide species is produced. Thus, the results

278 prove the accuracy of the coupling procedure and particularly the successful suppression of

279 significant mass balance errors that would result from the uncompensated adjustment of

280 concentrations to positive values during reaction calculations. 


\section{Application example: Drip irrigation and fertigation}

282 This example, reported by Hanson et al. (2006), simulates the fertigation of a tomato

283 plantation using a subsoil micro-irrigation system with periodic input of water and fertilizer

284 solution. The simulation of flow and transport was reproduced in COMSOL using the same

285 domain properties and parameters as in Hanson et al. (2006), who applied HYDRUS-2D

286 (Šimůnek et al., 1999). In contrast to Hanson et al. (2006), however, we implemented a

287 detailed description of geochemical through the coupling to IPhreeqc. This included solution

288 speciation with ion activity correction, kinetic redox transformations and cation exchange.

289 In agreement with Hanson et al. (2006), root water uptake was simulated using the spatial

290 root distribution model of Vrugt et al. (2001) in combination with the water stress response

291 function of Feddes et al. (1978). The model was implemented through the Matlab function

292 root_uptake.m, which is called from COMSOL at runtime (details on root water uptake are

293 given by Šimůnek and Hopmans, 2009; Šimůnek et al., 1999).

294

Fig. 5. Simulation domain with finite element mesh for drip irrigation simulation.

295

The simulation domain with 2665 nodes and 23985 degrees of freedom is displayed in Fig. 5 .

296 It represents a 2D slice of the soil system with axial symmetry along the left boundary.

297

Solutes and irrigation water enter the soil through the small half circle at $x=0 \mathrm{~m}, y=-0.2 \mathrm{~m}$

298 that represents the irrigation pipe with a diameter of $0.02 \mathrm{~m}$. Irrigation imposes a constant flux for $1.15 \mathrm{~d}$ intermittent with no flow periods of $2.35 \mathrm{~d}$. The fertilizer enters the domain for $0.575 \mathrm{~d}$ via a constant concentration boundary beginning $0.2875 \mathrm{~d}$ after start of irrigation periods. Details of the flow and solute transport properties are given by Hanson et al. (2006) and Gärdenäs et al. (2005) (simulation SUBTAPE, fertigation scenario M50).

Master species concentrations in the inflowing fertilizer solution were calculated by reacting $0.1449 \mathrm{~mol} \mathrm{KH}_{2} \mathrm{PO}_{4}, 0.0362 \mathrm{~mol} \mathrm{NH}_{4} \mathrm{NO}_{3}\left[\mathrm{AmmHNO}_{3}\right.$ ] and $0.0725 \mathrm{~mol}\left(\mathrm{NH}_{2}\right)_{2} \mathrm{CO}$ [Urea] with $1 \mathrm{~kg}$ of pure water. In order to prevent instantaneous hydrolysis and nitrification, urea (Urea) and ammonia (Amm) were defined as separate solution master species in IPhreeqc. In addition, the fertilizer solution and the fertilizer-free irrigation water were equilibrated with atmospheric $\mathrm{CO}_{2}\left(10^{-3.5} \mathrm{~atm}\right)$ and $\mathrm{O}_{2}\left(10^{-0.7} \mathrm{~atm}\right)$. The initial soil solution was assumed in equilibrium with atmospheric $\mathrm{O}_{2}\left(10^{-0.7} \mathrm{~atm}\right)$ and with $\mathrm{CO}_{2}$ from root respiration at a partial pressure $10^{-1.5} \mathrm{~atm}$. The latter value was chosen in agreement with the expected high actual evaporation ( $1200 \mathrm{~mm} \mathrm{yr}^{-1}$ ) for an irrigated tomato plantation in California, USA (Hanson et 
312 al., 2006) according to Brook et al. (1983). Properties of inflowing and initial solutions are

313 summarized in Table 1.

315 Geochemical solution properties. Master species concentrations in mol $\mathbf{k g}_{\text {water }}{ }^{-1}$, truncated to 2 digits.

316 Equilibrium solution speciation was defined as given in the thermodynamic database

317 phreeqc.dat, which is distributed with IPhreeqc. In order to suppress denitrification as in

318 Hanson et al. (2006), the equilibrium constant for the reaction $2 \mathrm{NO}_{3}^{-}+12 \mathrm{H}^{+}+10 \mathrm{e}^{-} \rightleftharpoons \mathrm{N}_{2}+$

$3196 \mathrm{H}_{2} \mathrm{O}$ was set to $10^{-1000}$. Kinetic hydrolysis of urea was simulated according to the reaction

Urea $+\mathrm{H}_{2} \mathrm{O} \rightarrow 2 \mathrm{Amm}+\mathrm{CO}_{2}$,

320 with the first-order rate expression $r_{\text {hyd }}\left(\mathrm{mol} \mathrm{s}^{-1} \mathrm{~m}^{-3}\right.$ ) (Hanson et al., 2006),

$r_{\text {hyd }}=k_{\text {hyd }} c^{\prime}{ }_{\text {Urea }} w$,

321 where $k_{\text {hyd }}$ is the reaction constant taken as $-0.35 \mathrm{~d}^{-1}$ and $c^{\prime}{ }_{\text {Urea }}$ is the molal urea

322 concentration. For the kinetic nitrification of ammonium to nitrate, we used the reaction

323 formula

$\mathrm{AmmH}^{+}+2 \mathrm{O}_{2}=\mathrm{NO}_{3}^{-}+2 \mathrm{H}^{+}+\mathrm{H}_{2} \mathrm{O}$

324 with the rate,

$r_{\text {nit }}=k_{\text {nit }} c^{\prime}{ }_{\text {Amm }} w \frac{c_{\mathrm{O}(0)}^{\prime}}{c_{\mathrm{O}(0)}^{\prime 0}}$.

325 The reaction constant $k_{\text {nit }}$ was set to $-0.2 \mathrm{~d}^{-1}$. In Eq. (15), $c^{\prime}{ }_{\mathrm{Amm}}$ and $c^{\prime}{ }_{\mathrm{O}(0)}$ are the molal

326 concentrations of ammonium and zero-valent oxygen, respectively, and ${c^{\prime}}^{0} \mathrm{O}(0)$ is the

327 concentration of zero-valent oxygen in the initial solution $\left(5.11 \times 10^{-4} \mathrm{~mol} \mathrm{~kg}_{\text {water }}{ }^{-1}\right)$. The last

328 term in Eq. (15) was introduced as an additional factor to the rate expression of Hanson et

329 al. (2006). Its purpose is to simulate free oxygen as a rate-limiting redox partner for the

330 kinetic oxidation of ammonium to nitrate.

331 In contrast to Hanson et al. (2006), who used a simple linear isotherm for ammonium

332 adsorption, we simulated adsorption of aqueous cations on negatively charged surfaces as a

333 cation exchange process (Appelo and Postma, 2005). Besides potassium and ammonium, 
free protons $\left(\mathrm{H}^{+}\right)$are included in the competition for the exchange sites in order to consider

335 the $\mathrm{pH}$ dependence of cation exchange and to be consistent with the conceptualization of

336 plant nutrient uptake via proton exchange (Hedrich and Schroeder, 1989). The cation

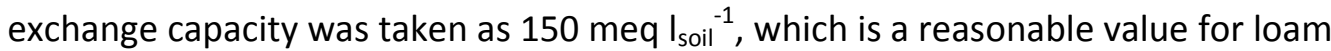

338 (Yukselen and Kaya, 2006). Exchange reaction formulas and ion affinities with suggested

339 values for proton exchange were those included in the database phreeqc.dat. The split-

340 operator time step $\Delta t$ for the alternation between transport and reactions calculations was

341 set to $0.01 \mathrm{~d}$.

Fig. 6. Normalized root distribution according to the Vrugt model (Vrugt et al., 2001) with parameters from Hanson et al. (2006).

344 Fig. 6 displays the normalized root distribution function used to describe water and solute

345 losses due to plant water uptake. As required by the Vrugt model (Vrugt et al., 2001), the

346 normalized root distribution integrates to unity over the simulation domain. Clearly visible

347 in Fig. 7 is the decrease of root density at depths $y<-0.2 \mathrm{~m}$, which is determined by the

348 parameter $z^{*}$ in Hanson et al. (2006).

Fig. 7. Moisture contents at 0 and 1.15 d, i.e., the beginning and end of the first irrigation period; white contours: lines of equal water contents.

351 The successful re-simulation of moisture dynamics was verified by visually comparing

352 moisture contents at the beginning and end of the first irrigation period with results

353 presented in Gärdenäs et al. (2005) and Hanson et al. (2006) (To follow this comparison the

354 reader is referred to the original references). The comparison reveals small discrepancies in

355 the dry part of the domain and along the right no-flow boundary, which can be attributed to

356 different domain discretizations and tolerance settings in the numerical methods.

357 Fig. 8. Solution master species concentrations 3.88, 4.63, 5, 7 and $28 \mathrm{~d}$ after beginning of fertigation cycles.

358 Molal concentrations of all solution master species, except for oxygen, hydrogen and

359 carbon, are displayed in Fig. 8. In the model phosphorus (P) is not involved in any kinetic

360 reactions or adsorption/desorption processes (since it does not adsorb to negatively

361 charged sorption sites) and therefore can be used as a reference for conservative solute

362 transport. By comparison to phosphorus and from concentrations of $\mathrm{O}(0)$ in Fig. 9 it is

363 evident that the kinetic transformation of ammonium to nitrate is limited by the available

$364 \mathrm{O}(0)$. Urea is clearly affected by hydrolysis with decreasing concentrations after fertigation

365 periods and increasing concentrations of ammonia (Amm). Potassium (K) is strongly 
366 retarded compared to phosphorus, with equal inflowing and initial concentrations due to 367 exchange with adsorbed protons and ammonia.

Fig. 9. Moisture contents, $\mathrm{pH}$ and exchanger composition $3.88,4.63,5,7$ and $28 \mathrm{~d}$ after beginning of fertigation cycles.

369 The exchanger composition, $\mathrm{pH}$ and molal concentrations of $\mathrm{O}(0)$ are presented in Fig. 9.

370 The soil's low initial $\mathrm{pH}$ originates from respiratory $\mathrm{CO}_{2}$. The decreasing $\mathrm{pH}$ behind the solute

371 front can be attributed to (i) oxidation of ammonium and (ii) the replacement of protons

372 from the surface exchange sites by ammonia and potassium. The latter can be interpreted

373 as a proton "snow plough" (Barry et al., 1983).

374 Low $\mathrm{pH}$ values due to nitrification and proton exchange may result in significant dissolution

375 of soil matrix minerals (e.g., calcite), which may act as $\mathrm{pH}$ buffers and release cations that

376 compete for adsorption sites and thereby reduce the adsorption efficiency of fertilizer ions.

377 Kinetic or equilibrium mineral reactions can be easily included in the simulation. However,

378 this was not taken into account in the given example because of the unknown mineral

379 composition of the substrate. Kinetic oxidation of ammonium to nitrate leads to a local

380 depletion in $\mathrm{O}(0)$ concentrations that inhibits further nitrification according to Eq. (15). Due

381 to the absence of other cations, the initial exchanger is entirely filled with $\mathrm{H}^{+}$. This situation

382 is unlikely to be valid in the field, but allows for more straightforward interpretation of this

383 illustration. A more realistic exchanger initialization requires measured exchanger

384 compositions or knowledge about the trace elements in the initial soil solution. Even though

385 the exchanger has a slightly larger affinity for potassium, ammonium dominates the

386 exchanger composition in the exterior of the solute ring that forms around the irrigation

387 pipe. This is due to the elevated concentration of ammonium from urea hydrolysis and

388 retardation of potassium, which shifts the concentration ratio towards ammonium. In

389 addition, the low $\mathrm{pH}$ values in this region favour the formation of ammonium as opposed to

390 non-adsorbing ammonia. Potassium is mainly adsorbed close to the irrigation pipe, where

391 ammonium concentrations are low. The region at $x=0.6 \mathrm{~m}, y=0 \mathrm{~m}$ remains extremely dry

392 (cf. Fig. 7). Therefore, it is effectively inert towards changes in geochemical conditions (e.g.,

$393 \mathrm{pH}, \mathrm{O}(0)$ content).

394 Results of the present simulation and those of Hanson et al. (2006) show roughly similar

395 patterns for nitrate and urea. However, in our simulations nitrate concentrations at 7 and 28 
d are considerably lower in the direct vicinity of the supply tube, where it shows the highest concentrations in Hanson et al. (2006). The lower concentration in our simulations is expected considering the irrigation/fertigation scheme where the fertilizer is flushed into the soil with pure water following its application.

\section{Concluding remarks}

401 The application example in section 4 verifies the coupling of unsaturated flow and

402 multispecies solute transport in COMSOL with the geochemical modelling framework

403 IPhreeqc. Minor differences to the global implicit solution are introduced through operator

404 splitting and can be controlled by the magnitude of the splitting time step $\Delta t$. Furthermore,

405 it was shown that the constraint of positive concentrations in IPhreeqc in combination with

406 negative concentrations from COMSOL's solute transport scheme does not lead to

407 significant mass balance errors.

408 Section 5 shows the enhanced geochemical capabilities resulting from the coupling between

409 COMSOL and IPhreeqc in a complex simulation of unsaturated flow and solute transport.

410 The successful replication of the moisture content distribution from Hanson et al. (2006)

411 illustrates the capabilities of COMSOL's Earth Science Module to simulate unsaturated flow

412 processes. Further, the implementation of pressure- and root distribution-dependent root-

413 water uptake demonstrates the convenience of COMSOL to extend predefined vadose zone 414 processes through user-defined Matlab functions.

415 Due to the capabilities of COMSOL to simulate a wide variety of environmental flow 416 phenomena (e.g., two-phase flow, fracture flow, flow according to the Darcy, Brinkman or 417 incompressible Navier-Stokes equations), the presented coupling procedure can be utilized 418 as a general guide for linking flow and transport calculations in COMSOL to geochemical 419 reactions in IPhreeqc.

\section{Acknowledgments}

421 The authors wish to thank David Parkhurst and Tony Appelo for their assistance with the 422 coupling procedure and the prompt implementation of the required features into PHREEQC. 
424

425

426

427

428

429

430

431

432

433

434

435

436

437

438

439

440

441

442

443

444

445

446

447

448

449

450

451

452

453

454

455

456

457

458

459

460

461

462

463

464

465

466

\section{References}

Appelo, C.A.J., Postma, D., 2005. Geochemistry, Groundwater and Pollution, 2nd ed. Balkema, Leiden, Netherlands, 649 pp.

Barry, D.A., 1992. Modelling contaminant transport in the subsurface: Theory and computer programs, In: Ghadiri, H., Rose, C.W. (Eds.), Modelling Chemical Transport in Soil: Natural and Applied Contaminants. Lewis Publishers: Boca Raton, Florida, pp. 105144.

Barry, D.A., Bajracharya, K., Crapper, M., Prommer, H., Cunningham, C.J., 2000. Comparison of split-operator methods for solving coupled chemical non-equilibrium reaction/groundwater transport models. Mathematics and Computers in Simulation 53(1-2) 113-127.

Barry, D.A., Miller, C.T., Culligan-Hensley, P.J., 1996. Temporal discretisation errors in noniterative split-operator approaches to solving chemical reaction groundwater transport models. Journal of Contaminant Hydrology 22(1-2) 1-17.

Barry, D.A., Miller, C.T., Culligan, P.J., Bajracharya, K., 1997. Analysis of split operator methods for nonlinear and multispecies groundwater chemical transport models. Mathematics and Computers in Simulation 43(3-6) 331-341.

Barry, D.A., Starr, J.L., Parlange, J.Y., Braddock, R.D., 1983. Numerical analysis of the snowplow effect. Soil Science Society of America Journal 47(5) 862-868.

Bear, J., 1972. Dynamics of Fluids in Porous Media. Elsevier Scientific Publishing Co, New York, $764 \mathrm{pp}$.

Bear, J., 2007. Hydraulics of Groundwater, Reprint ed. Dover Publications, Mineola, NY, 569 pp.

Bear, J., Bachmat, Y., 1998. Introduction to Modeling of Transport Phenomena in Porous Media, Reprinted ed. Kluwer, Dordrecht, $553 \mathrm{pp}$.

Brook, G.A., Folkoff, M.E., Box, E.O., 1983. A world model of soil carbon-dioxide. Earth Surface Processes and Landforms 8(1) 79-88.

Brooks, R.H., Corey, A.T., 1964. Hydraulic properties of porous media, Hydrological Paper. Civil Engineering Department, Colorado State University: Fort Collins, Colorado.

Brussaard, L., Pulleman, M.M., Ouédraogo, É., Mando, A., Six, J., 2007. Soil fauna and soil function in the fabric of the food web. Pedobiologia 50(6) 447-462.

Charlton, S.R., Parkhurst, D.L., 2010. Modules based on the geochemical model PHREEQC for use in scripting languages and reactive-transport calculations. Environmental Modelling \& Software, under review.

COMSOL Multiphysics ${ }^{\circledR}$, 2008a. Pesticide transport and reaction in soil, Earth Science Module Model Library.

COMSOL Multiphysics ${ }^{\circledR}$, 2008b. Variably saturated flow and transport: Sorbing solute, Earth Science Module Model Library.

COMSOL Multiphysics , 2010. http://www.comsol.com/, last accessed: 22.06.2010.

Corey, A.T., Auvermann, B.W., 2003. Transport by advection and diffusion revisited. Vadose Zone Journal 2(4) 655-663.

Donea, J., Huerta, A., 2004. Finite Element Methods for Flow Problems. Wiley, England, 350 pp. 
Dzombak, D.A., Morel, F.M.M., 1990. Surface Complexation Modeling : Hydrous Ferric Oxide. Wiley, New York, 393 pp.

Feddes, R.A., Kowalik, P.J., Zaradny, H., 1978. Simulation of Field Water Use and Crop Yield. Pudoc, Wageningen.

Freedman, V., Ibaraki, M., 2002. Effects of chemical reactions on density-dependent fluid flow: on the numerical formulation and the development of instabilities. Advances in Water Resources 25(4) 439-453.

Gärdenäs, A.I., Hopmans, J.W., Hanson, B.R., Šimůnek, J., 2005. Two-dimensional modeling of nitrate leaching for various fertigation scenarios under micro-irrigation. Agricultural Water Management 74(3) 219-242.

Gustafsson, J.P., 2010. Visual MINTEQ version 3.0, http://www.Iwr.kth.se/English/OurSoftware/vminteq/, last accessed: 22.06.2010.

Hanson, B.R., Šimůnek, J., Hopmans, J.W., 2006. Evaluation of urea-ammonium-nitrate fertigation with drip irrigation using numerical modeling. Agricultural Water Management 86(1-2) 102-113.

Harbaugh, A.W., Banta, E.R., Hill, M.C., McDonald, M.G., 2000. MODFLOW-2000, the U.S. Geological Survey modular ground-water model: User guide to modularization concepts and the ground-water flow process. U.S. Geological Survey.

Hedrich, R., Schroeder, J.I., 1989. The physiology of ion channels and electrogenic pumps in higher-plants. Annual Review of Plant Physiology and Plant Molecular Biology 40 539-569.

Hiemstra, T., van Riemsdijk, W.H., Bolt, G.H., 1989. Multisite proton adsorption modeling at the solid-solution interface of (hydr)oxides - A new approach. 1. Model description and evaluation of intrinsic reaction constants. Journal of Colloid and Interface Science 133(1) 91-104.

Huyakorn, P.S., Pinder, G.F., 1983. Computational Methods in Subsurface Flow. Academic Press, London, UK, $473 \mathrm{pp}$.

Jacques, D., Šimůnek, J., 2010. Notes on HP1 - a software package for simulating variablysaturated water flow, heat transport, solute transport and biogeochemistry in porous media Waste and Disposal, SCK•CEN: Mol, Belgium.

Jacques, D., Šimůnek, J., Mallants, D., van Genuchten, M.T., 2006. Operator-splitting errors in coupled reactive transport codes for transient variably saturated flow and contaminant transport in layered soil profiles. Journal of Contaminant Hydrology 88(3-4) 197-218.

Jacques, D., Šimůnek, J., Mallants, D., van Genuchten, M.T., 2008. Modeling coupled hydrologic and chemical processes: Long-term uranium transport following phosphorus fertilization. Vadose Zone Journal 7(2) 698-711.

Langmuir, D., 1997. Aqueous Environmental Geochemistry. Prentice Hall, Upper Saddle River, 600 pp.

Letey, J., Kemper, W.D., Noonan, L., 1969. Effect of osmotic pressure gradients on water movement in unsaturated soil. Soil Science Society of America Proceedings 33(1) 1518.

Mao, X., Prommer, H., Barry, D.A., Langevin, C.D., Panteleit, B., Li, L., 2006. Threedimensional model for multi-component reactive transport with variable density groundwater flow. Environmental Modelling \& Software 21(5) 615-628.

Matlab , 2010. The MathWorks, http://www.mathworks.com/, last accessed: 22.06.2010. 
513

514

515

516

517

518

519

520

521

522

523

524

525

526

527

528

529

530

531

532

533

534

535

536

537

538

539

540

541

542

543

544

545

546

547

548

549

550

551

552

553

554

555

556

557

Mayer, K.U., Frind, E.O., Blowes, D.W., 2002. Multicomponent reactive transport modeling in variably saturated porous media using a generalized formulation for kinetically controlled reactions. Water Resources Research 38(9) 131-1321.

Meeussen, J.C.L., 2003. ORCHESTRA: An object-oriented framework for implementing chemical equilibrium models. Environmental Science \& Technology 37(6) 1175-1182.

Miller, C.T., Christakos, G., Imhoff, P.T., McBride, J.F., Pedit, J.A., Trangenstein, J.A., 1998. Multiphase flow and transport modeling in heterogeneous porous media: Challenges and approaches. Advances in Water Resources 21(2) 77-120.

Millington, R.J., Quirk, J.P., 1961. Permeability of porous solids. Transactions of the Faraday Society 57 1200-1207.

Parkhurst, D.L., 2010. Personal Communication.

Parkhurst, D.L., Appelo, C.A.J., 1999. User's guide to PHREEQC (version 2): A computer program for speciation, batch-reaction, one-dimensional transport, and inverse geochemical calculations. U.S. Geological Survey: Denver, Colorado.

Parkhurst, D.L., Kipp, K.L., Engesgaard, P., Charlton, S.R., 2004. PHAST - A Program for simulating ground-water flow, solute transport, and multicomponent geochemical reactions. U.S. Geological Survey: Denver, Colorado.

Perrochet, P., Berod, D., 1993. Stability of the standard Crank-Nicolson-Galerkin scheme applied to the diffusion-convection equation - Some new insights. Water Resources Research 29(9) 3291-3297.

Prommer, H., Barry, D.A., Zheng, C., 2003. MODFLOW/MT3DMS-based reactive multicomponent transport modeling. Ground Water 41(2) 247-257.

Prommer, H., Davis, G.B., Barry, D.A., 1999. PHT3D - A three-dimensional biogeochemical transport model for modelling natural and enhanced remediation, In: Johnston, C.D. (Ed.), Contaminated Site Remediation: Challenges Posed by Urban and Industrial Contaminants. Centre for Groundwater Studies: Fremantle, Western Australia, pp. 351-358.

Saaltink, M.W., Batlle, F., Ayora, C., Carrera, J., Olivella, S., 2004. RETRASO, a code for modeling reactive transport in saturated and unsaturated porous media. Geologica Acta 2(3) 235-251.

Šimůnek, J., Bradford, S.A., 2008. Vadose zone modeling: Introduction and importance. Vadose Zone Journal 7(2) 581-586.

Šimůnek, J., Hopmans, J.W., 2009. Modeling compensated root water and nutrient uptake. Ecological Modelling 220(4) 505-521.

Šimůnek, J., Jacques, D., van Genuchten, M.T., Mallants, D., 2006. Multicomponent geochemical transport modeling using HYDRUS-1D and HP1. Journal of the American Water Resources Association 42(6) 1537-1547.

Šimůnek, J., Šejna, M., Saito, H., Sakai, M., van Genuchten, M.T., 2009. The HYDRUS-1D software package for simulating the movement of water, heat, and multiple solutes in variably saturated media, Version 4.0. Department of Environmental Sciences, University of California Riverside: Riverside, California.

Šimůnek, J., Šejna, M., van Genuchten, M.T., 1999. The HYDRUS-2D software package for simulating the two-dimensional movement of water, heat, and multiple solutes in variably-saturated media, Version 2.0. Department of Environmental Sciences, University of California Riverside: Riverside, California. 
Šimůnek, J., Vogel, T., van Genuchten, M.T., 1994. The SWMS-2D code for simulating water flow and solute transport in two-dimensional variably saturated media, Version 1.21. U.S. Salinity Laboratory: Riverside, CA.

Steefel, C.I., MacQuarrie, K.T.B., 1996. Approaches to modeling of reactive transport in porous media, In: Lichtner, P.C., Steefel, C.I., Oelkers, E.H. (Eds.), Reactive Transport in Porous Media. Reviews in Mineralogy, 34. Mineralogical Society of America: Washington DC, pp. 82-129.

Valocchi, A.J., Malmstead, M., 1992. Accuracy of operator splitting for advection-dispersionreaction problems. Water Resources Research 28(5) 1471-1476.

van der Lee, J., 1998. Thermodynamic and mathematical concepts of CHESS. Ecole des Mines de Paris: Fontainebleau, France.

van Genuchten, M.T., 1980. Closed-form equation for predicting the hydraulic conductivity of unsaturated soils. Soil Science Society of America Journal 44(5) 892-898.

Voss, C.I., Provost, A.M., 2008. SUTRA: A model for saturated-unsaturated, variable-density ground-water flow with solute or energy transport. U.S. Geological Survey: Reston, Virginia.

Vrugt, J.A., Hopmans, J.W., Šimůnek, J., 2001. Calibration of a two-dimensional root water uptake model. Soil Science Society of America Journal 65(4) 1027-1037.

Wissmeier, L., Barry, D.A., 2010. Implementation of variably saturated flow into PHREEQC for the simulation of biogeochemical reactions in the vadose zone. Environmental Modelling \& Software 25(4) 526-538.

Wissmeier, L., Brovelli, A., Robinson, C., Stagnitti, F., Barry, D.A., 2009. Pollutant fate and transport in the subsurface, Modelling of Pollutants in Complex Environmental Systems. ILM Publications, pp. 99-143.

Yeh, G.T., Tripathi, V.S., 1989. A critical evaluation of recent developments in hydrogeochemical transport models of reactive multi-chemical components. Water Resources Research 25(1) 93-108.

Yukselen, Y., Kaya, A., 2006. Prediction of cation exchange capacity from soil index properties. Clay Minerals 41(4) 827-837. 


\section{Table}

Table 1

Geochemical solution properties. Master species concentrations in mol(kg water $)^{-1}$, truncated to 2 digits.

\begin{tabular}{llll}
\hline & Fertilizer solution & Irrigation water & Initial soil solution \\
\hline $\mathrm{pH}$ & 3.844 & 5.659 & 4.660 \\
$\mathrm{pe}$ & 16.78 & 14.96 & 15.96 \\
$\mathrm{O}$ & 56.12 & 55.51 & 55.51 \\
$\mathrm{H}$ & 111.34 & 111.01 & 111.02 \\
$\mathrm{P}$ & 0.15 & 0.00 & 0.00 \\
$\mathrm{~K}$ & 0.15 & 0.00 & 0.00 \\
$\mathrm{Amm}$ & $3.62 \times 10^{-2}$ & 0.00 & 0.00 \\
Urea & $7.25 \times 10^{-2}$ & 0.00 & 0.00 \\
$\mathrm{~N}$ & $3.62 \times 10^{-2}$ & 0.00 & 0.00 \\
$\mathrm{C}$ & $1.04 \times 10^{-5}$ & $1.30 \times 10^{-5}$ & $1.10 \times 10^{-3}$ \\
\hline
\end{tabular}




\section{Figure Captions}

Fig. 1. Program flow and structure.

Fig. 2. Simulation domain with finite element mesh for pesticide simulation. The source zone is indicated by the thick line at $y=0$.

Fig. 3. Aldicarb reaction chain.

Fig. 4. Comparison of concentrations from the coupling procedure and COMSOL alone eight $d$ after beginning of infiltration.

Fig. 5. Simulation domain with finite element mesh for drip irrigation simulation.

Fig. 6. Normalized root distribution according to the Vrugt model (Vrugt et al., 2001) with parameters from Hanson et al. (2006).

Fig. 7. Moisture contents at 0 and 1.15 d, i.e., the beginning and end of the first irrigation period; white contours: lines of equal water contents.

Fig. 8. Solution master species concentrations $3.88,4.63,5,7$ and $28 \mathrm{~d}$ after beginning of fertigation cycles.

Fig. 9. Moisture contents, $\mathrm{pH}$ and exchanger composition 3.88, 4.63, 5, 7 and $28 \mathrm{~d}$ after beginning of fertigation cycles. 


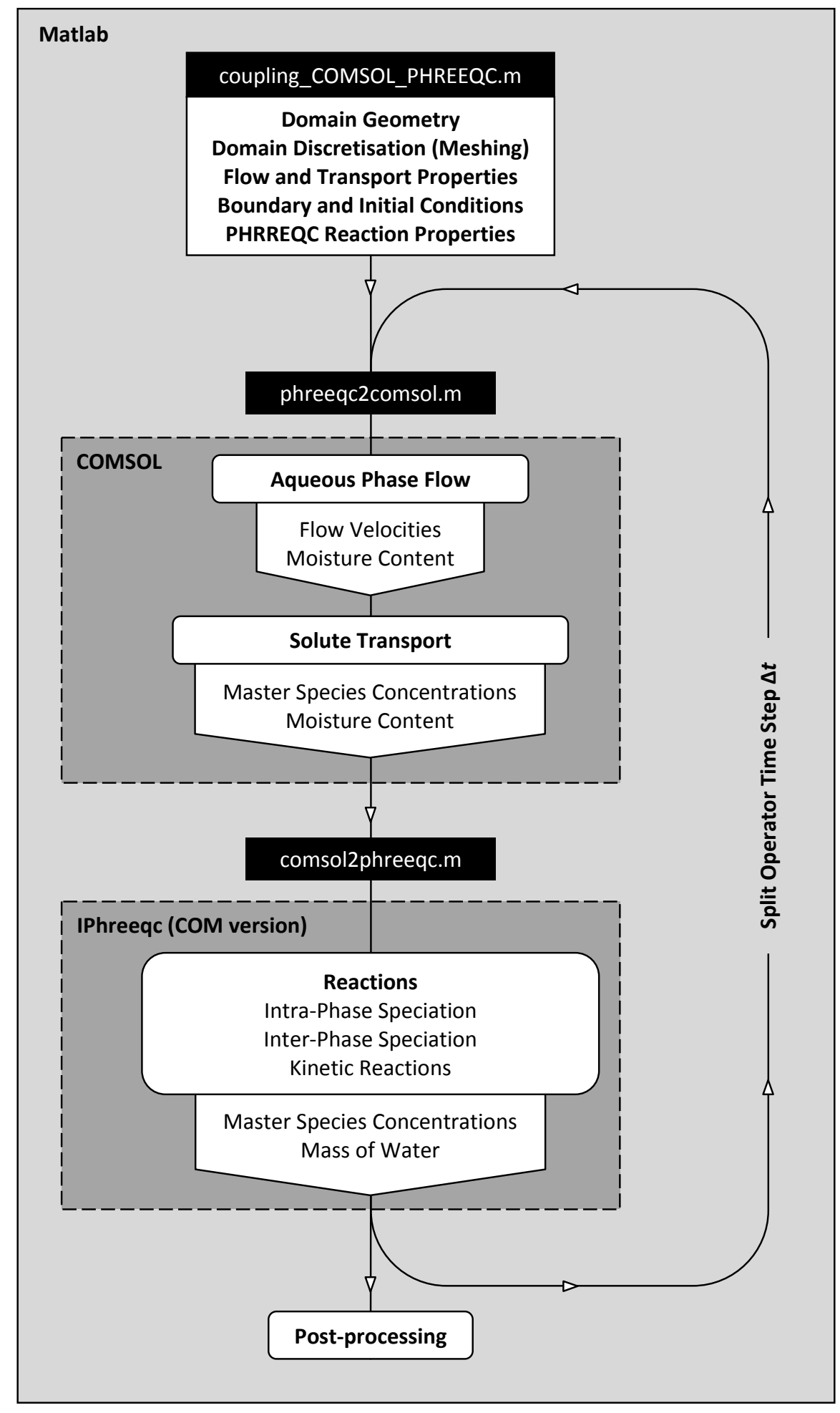




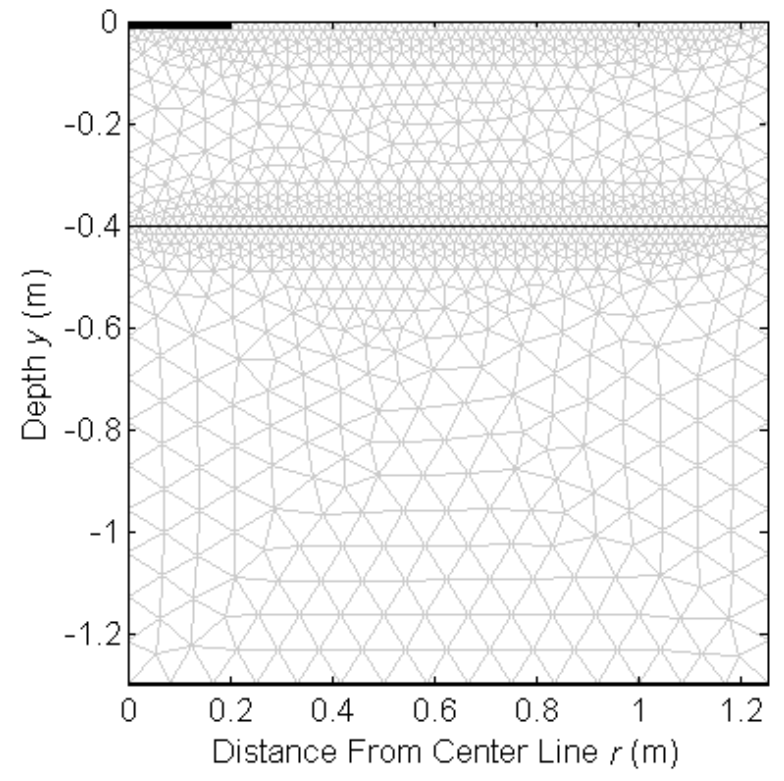




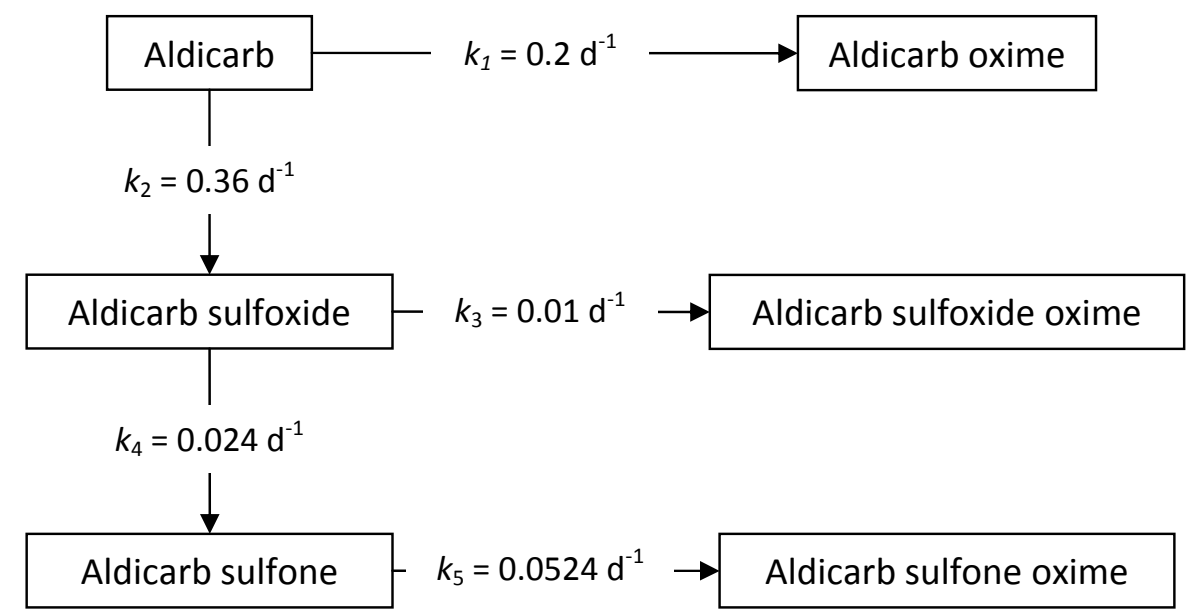



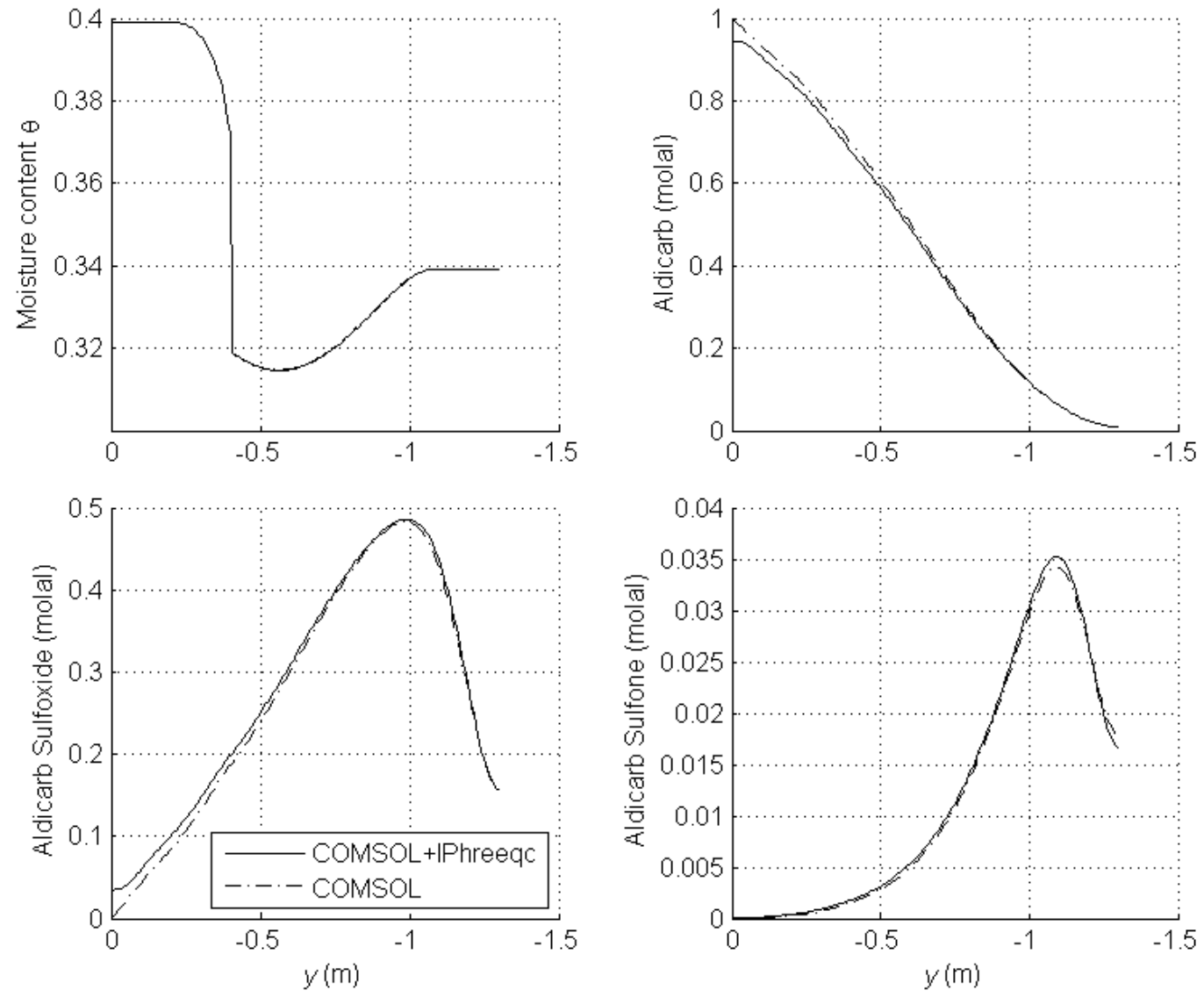


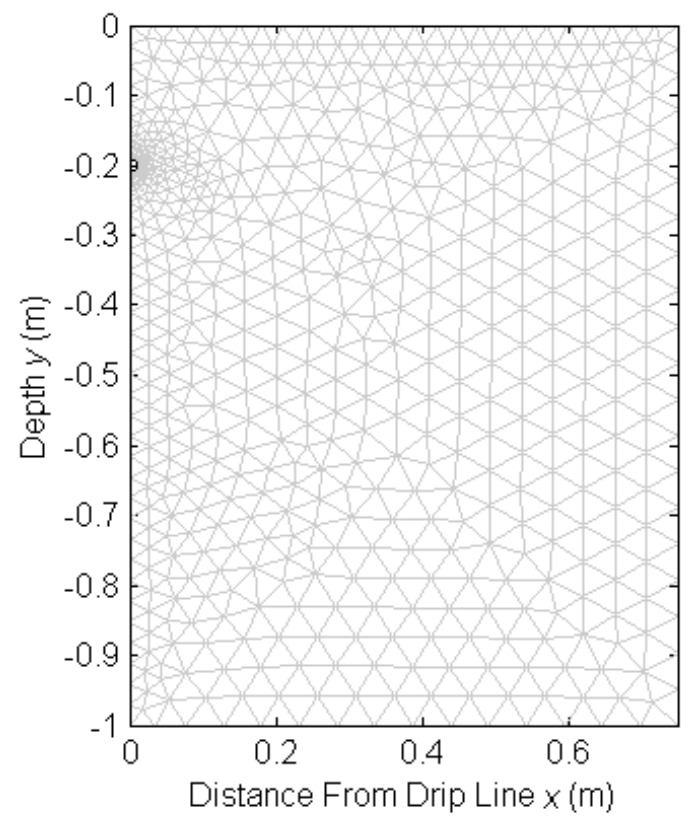



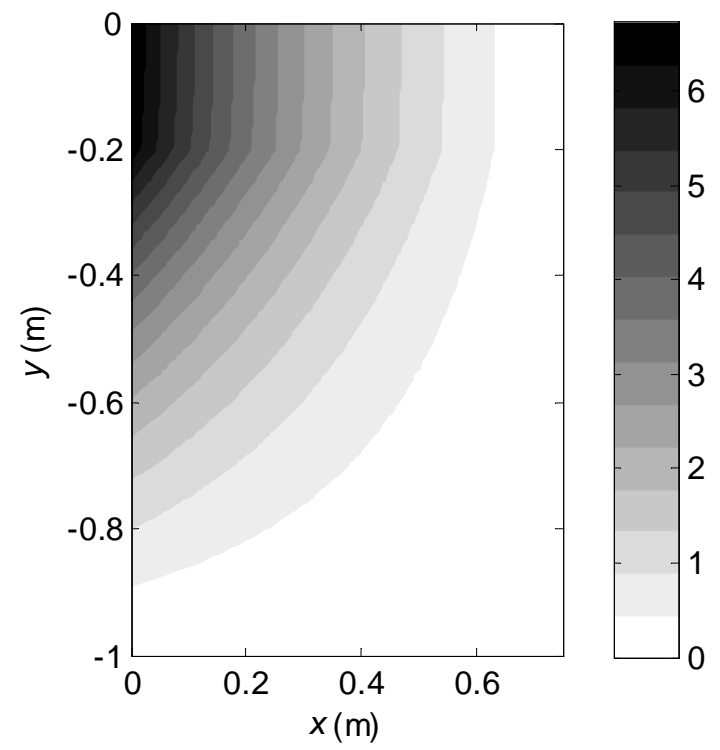

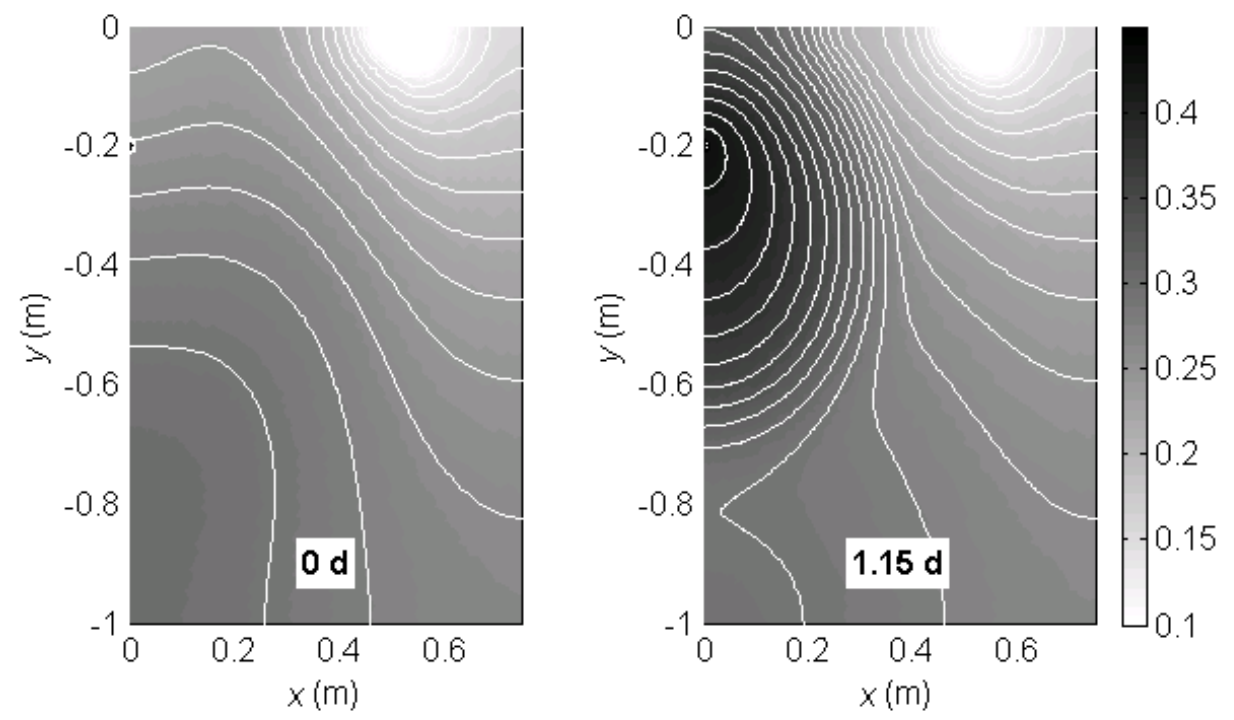

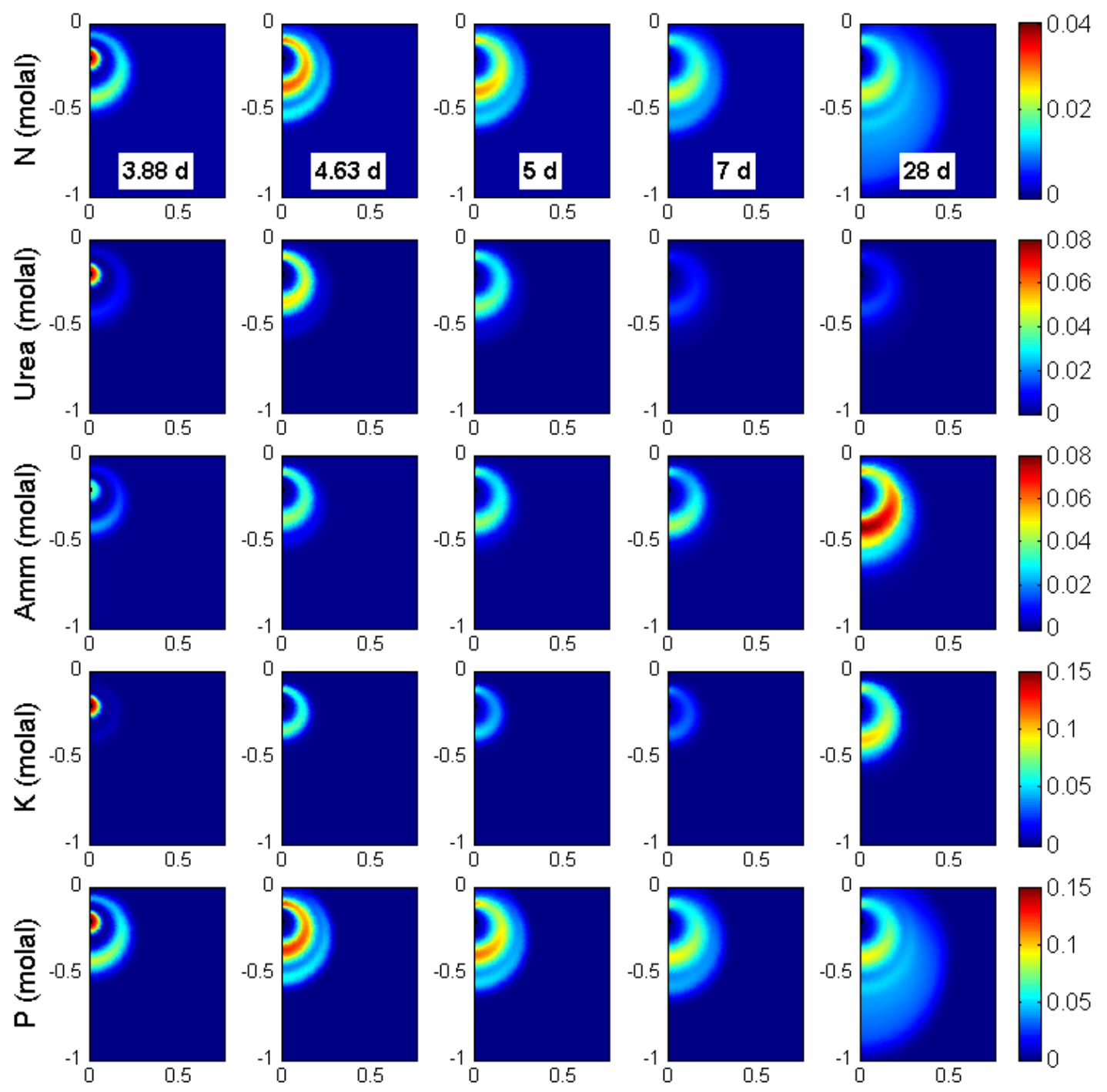


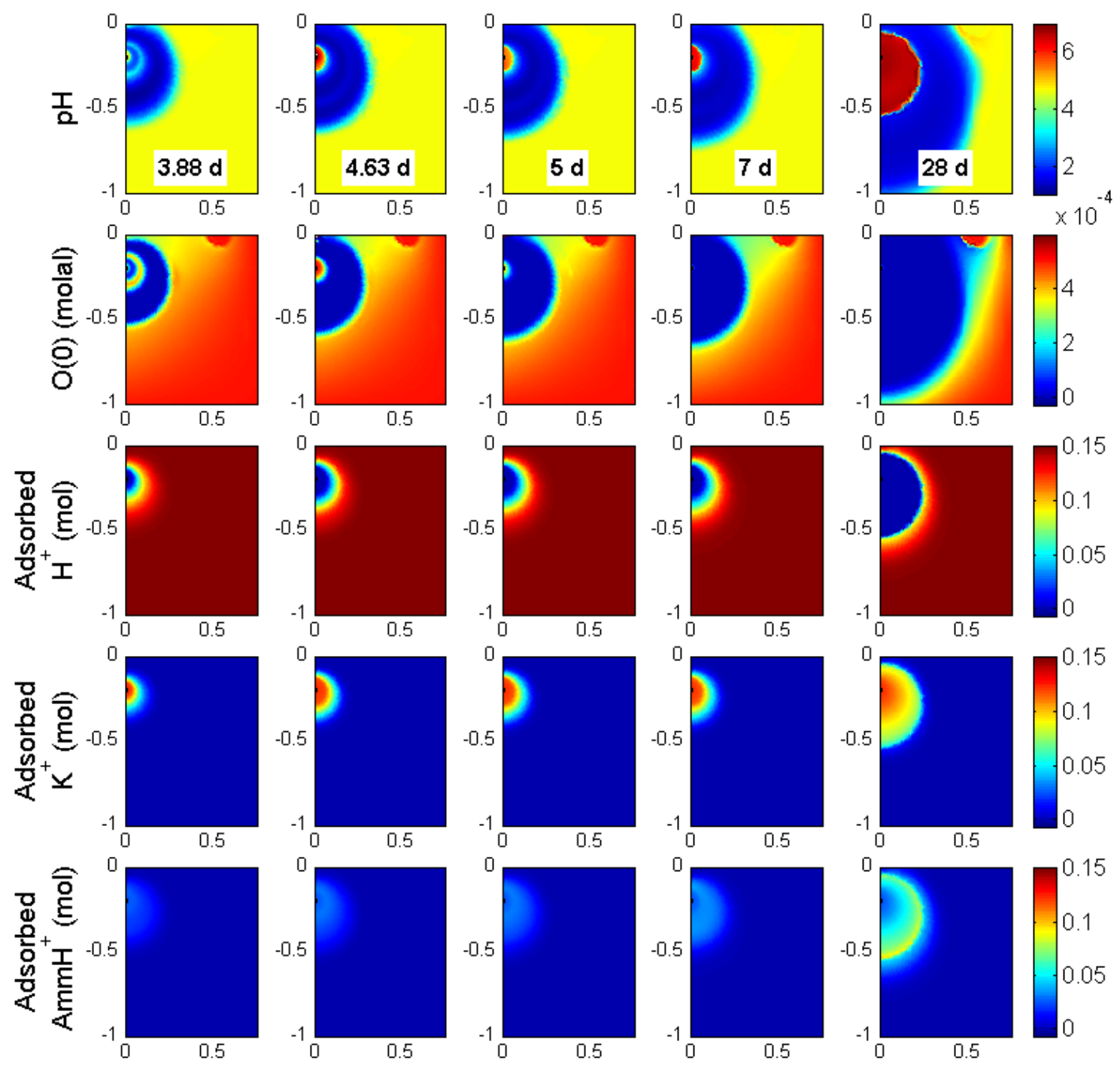

